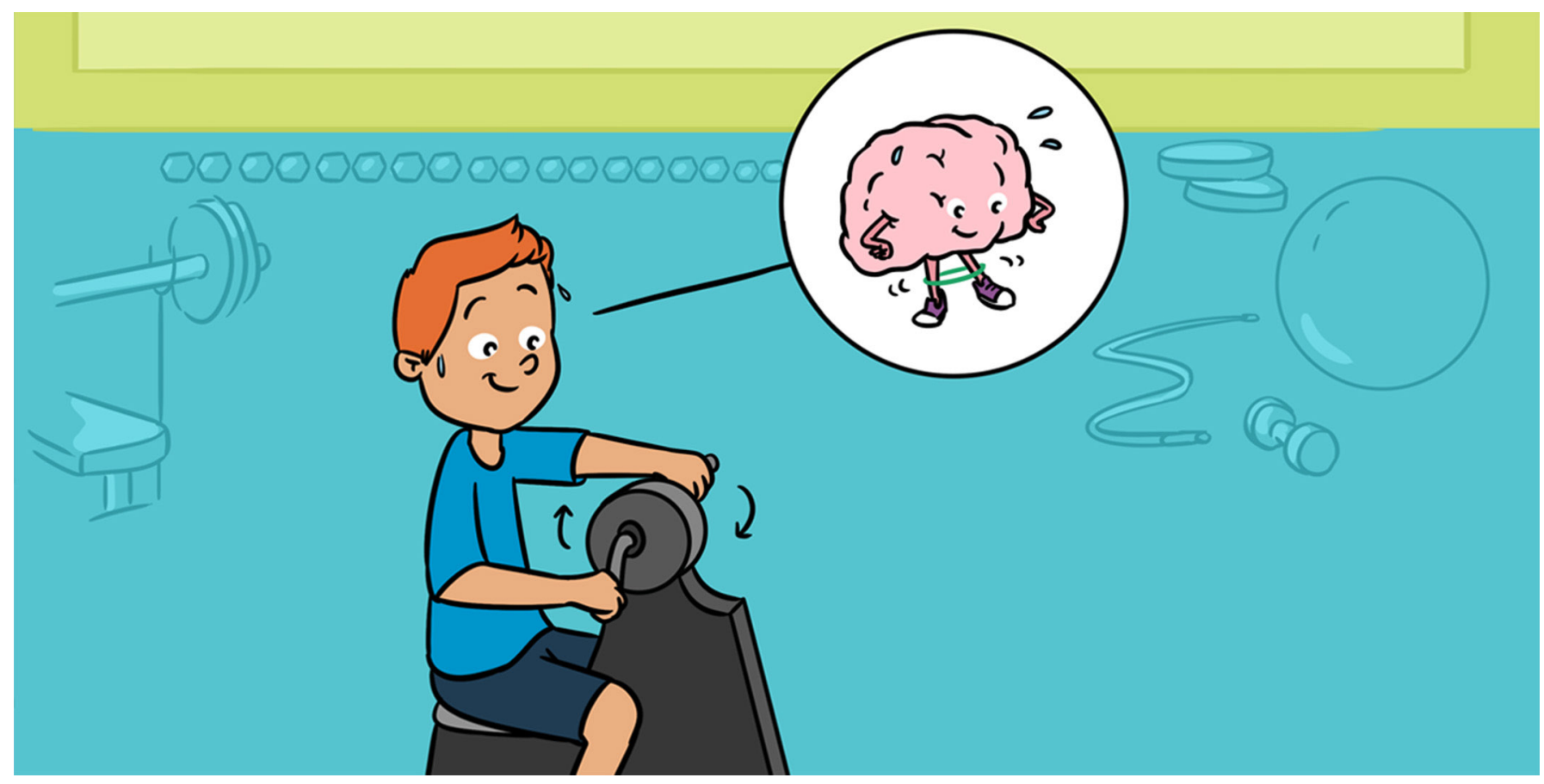

\title{
HOW THE ARMS HELP THE LEGS GET BETTER AT WALKING AFTER STROKE
}

\section{Gregory E. P. Pearcey ${ }^{1,2,3}$ and E. Paul Zehr $r^{1,2,3,4 *}$}

${ }^{1}$ Rehabilitation Neuroscience Laboratory, University of Victoria, Victoria, BC, Canada

${ }^{2}$ Human Discovery Science, International Collaboration on Repair Discoveries, Vancouver, BC, Canada

${ }^{3}$ Centre for Biomedical Research, University of Victoria, Victoria, BC, Canada

${ }^{4}$ Division of Medical Sciences, University of Victoria, Victoria, BC, Canada

\section{YOUNG REVIEWERS:}

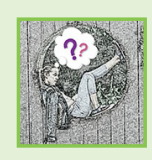

ALYSSA

AGE: 12

ARITRO

AGE: 10
If you have a family member or friend who has had a stroke, you may have wondered "what is a stroke?" and "can you get better after a stroke?" You also might have noticed that people cannot walk as well after a stroke. This is because a stroke is an injury to the brain. When a person's brain is injured, it is difficult for that person to control his or her muscles. But! Even though there are difficulties walking after a stroke, walking can still be improved. In the following article, we explain how and why training the arms can help someone get better at walking after a stroke.

\section{THE BACKGROUND}

Once upon a time, our ancestors walked on all four limbs, just like a cat or a dog. That is right, we used to walk on both our hands and our feet! 
This is because humans are animals, too! As millions of years passed, we began to walk on two feet. This allowed us to use our hands for other tasks, like waving, carrying, and throwing, as we move about. Even though walking on two feet is different from other animals, the way in which we control walking is closely related to that of animals that walk on all fours.

\section{THE BRAIN IS IMPORTANT, BUT OTHER PARTS OF THE NERVOUS SYSTEM ARE TOO!}

It is very common for people to think that the brain controls all of the movements that we make. When we think about moving, signals travel from the brain travel down to the spinal cord through nerves (almost like telephone wires). The spinal cord acts like a freeway with many exits in both directions. In one direction, information from the senses travels to the brain, and in the other direction, signals are carried from the brain to control the muscles. The actions of these muscles are what cause the arms and legs to move. However, the brain is not always required to cause movement. By examining animals, scientists discovered that complex groups of cells within the spinal cord can control walking [1]. It turns out that the main job of controlling walking is done by the spinal cord, and not the brain. Many animals are fully capable of walking without signals from the brain. Have you ever heard of the saying "running around like a chicken with its head cut off?" It is actually possible! This is possible because those groups of cells within the spinal cord can control movement of the legs without signals from the brain. We do, however, need to send signals from the brain to tell the spinal cord to start walking!

Once the signals from the brain start the movement, the spinal cord can coordinate movement between all four limbs. This coordination ensures that there is alternating activity between the muscles that bend and straighten the legs on the left and right side of the body. This is made possible because of nerve connections between the limbs. These connections share information that we sense about our surroundings, which can then increase or decrease activity of muscles during walking. This is useful when we need to quickly respond to an obstacle or hazard. For example, have you ever had a close call by stubbing your toe and almost falling on your face while walking? Then, without thinking, you move your limbs and prevent yourself from falling. This automatic reaction to tripping happens within the spinal cord, through the nerve connections between your limbs. So, it is clearly very important that humans have groups of cells within the spinal cord and nerve connections between limbs, both to help generate walking and to prevent falls. Studying the groups of cells in the spinal cord and 
Figure 1

The brain, spinal cord, and information from the moving limbs interact to control and maintain rhythmic movements. These rhythmic movements can include activities such as walking, running, swimming, and cycling, which are shown in the center of the diagram.

\section{STROKE}

A medical condition that is caused when blood stops flowing to part of your brain, causing damage to brain cells.

\section{REHABILITATION}

The action of restoring someone to normal health by training or therapy

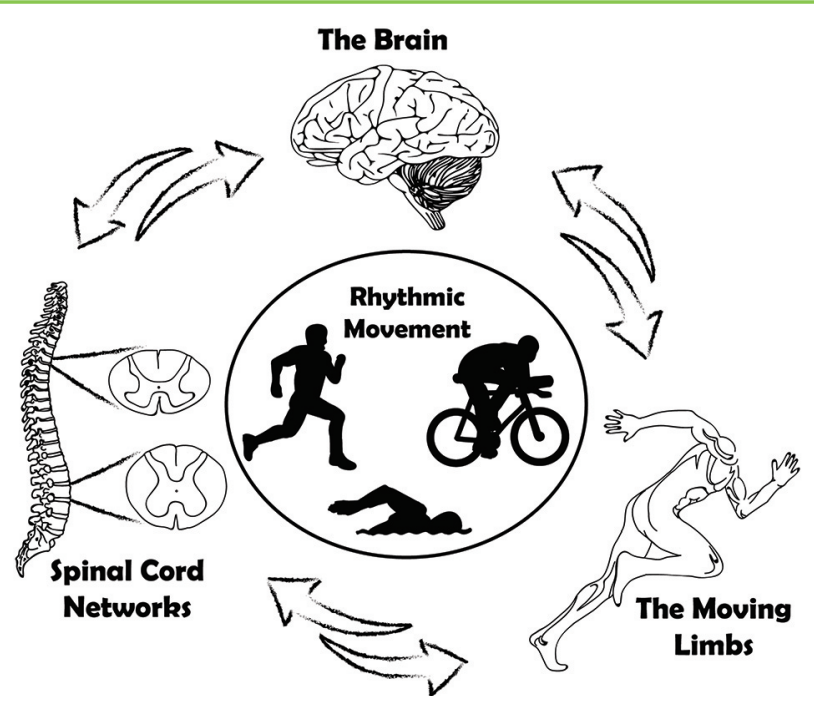

Figure 1

the nerve connections between the limbs can guide scientists to help people get better at walking after an injury, like a stroke. Figure 1 shows how the brain, the spinal cord, and the information from the moving limbs interact to produce and maintain walking, running, swimming, and cycling.

\section{WHAT IS A STROKE, AND HOW DOES IT AFFECT A PERSON'S ABILITY TO WALK?}

A stroke is one example of a brain injury that weakens the connections between parts of the brain, and between the brain and the muscles that allow us to move. The most common kind of stroke is called an "ischemic" stroke. Blood in the brain flows through blood vessels, similar to water running through a hose. Sometimes, blood clots floating in the blood can clog the blood vessels and prevent blood from flowing to some parts of the brain. This lack of blood flow prevents nutrients and energy from getting to those areas of the brain. Brain cells that are unable to get healthy blood will die. If brain cells die, they cannot communicate information to other parts of the brain or the body.

Because of weakened connections between the brain and body after a stroke, people can have difficulty doing tasks that were easy before. For example, a person can have difficulties walking short distances or even standing. This is because the signals coming from the brain that normally control walking are weakened by the stroke. However, these difficulties with walking do not have to last forever. The ability to walk can be recovered after a stroke because the brain and spinal cord can change when a person does physical exercise as rehabilitation. Rehabilitation means to recover function after an injury. There are 
many types of tools that doctors can use to help with rehabilitation. Unfortunately, many of these tools are very expensive and not very many stroke patients get to use them.

A stroke (and other brain injuries, too) can weaken connections from the brain to the spinal cord and the muscles, as well as weaken the ability of the brain and spinal cord to receive information from the limbs about movement. However, inside the spinal cord, those groups of cells and connections between the limbs remain. Doing movements that connect the arms and legs-like walking or cycling-can strengthen the connections in the nervous system.

\section{CAN TRAINING HELP A PERSON AFTER A STROKE?}

Many experiments show that movement of the arms changes the activity of muscles in the legs [2]. This happens even after a stroke [3]. Recovery from a stroke can occur without rehabilitation, but rehabilitation has been shown to increase the rate of recovery and the amount of recovery that a stroke patient can achieve. Even many years after a stroke, rehabilitation can help. We previously studied how a type of rehabilitation that involved training the arms and legs together on a special bicycle helped people get better at walking after stroke $[4,5]$. We discovered that this training improved the strength of the arms and legs, the ability to walk, and the nerve connections between the arms and legs. However, we did not know whether performing training with only the arms could help with walking after a stroke. Training with only the arms can be done at most community gyms, making this type of rehabilitation accessible to many people recovering from strokes.

\section{CAN TRAINING JUST THE ARMS HELP A PERSON GET BETTER AT WALKING AFTER A STROKE?}

Our purpose was to find out if training just the arms could help people who had strokes get better at walking [6]. To test this, we recruited 19 people who had a stroke at least 6 months before the experiment. Each person visited our laboratory three times before the training started. During those three visits, we measured their ability to walk, the strength in their arms and legs, how well they could control their muscles during walking, and the strength of the nerve connections between their arms and legs.

To measure their ability to walk, we timed how long it took them to walk $10 \mathrm{~m}$ and measured how far they could walk in $6 \mathrm{~min}$. 
To measure the strength in their arms and legs, we had them squeeze a specialized handle with each hand as hard as they could, and push/ pull with their ankles as hard as they could within a specialized boot. To measure control of their muscles, we placed sensors on the skin that could record the activity of the muscles. To measure connections between the arms and legs, we applied a small shock to their hands and measured the activity of the muscles in the other limbs after the shock.

Once we got measures from the participants, they started an arm cycling training program. The training consisted of cycling with the arms at a moderate pace, meaning that participants could do the task for 30 min without getting tired. This training happened three times each week for 5 weeks and every session was 30 min long. After the training, we tested the participants again with the measures used before the training, to see if they had any improvements.

\section{TRAINING JUST THE ARMS CAN HELP WITH WALKING!}

To see the effects of the training program, see Figure 2. Our participants struggled to walk prior to training. But after training, our participants could walk faster and for longer distances. They also increased the strength in their arms and legs, strengthened the connections between their arms and legs, and improved their ability to control their muscles during walking. All of these changes are similar to what happens when people train their legs. The interesting part, however, is that these people did not even use their legs - they just used the nerve connections within the spinal cord and from the arms to the legs! See Figure 3 to see how the nerve connections between the limbs are strengthened when participants train just the arms after stroke.

Figure 2

A cartoon of the improvements that can occur when someone trains their arms after a stroke. On the left, the old lady has trouble walking and requires her walker. In the middle, she performs arm cycling training as rehabilitation. On the right, she has improved her ability to walk and her strength. Out of excitement, she holds her walker up in the air!

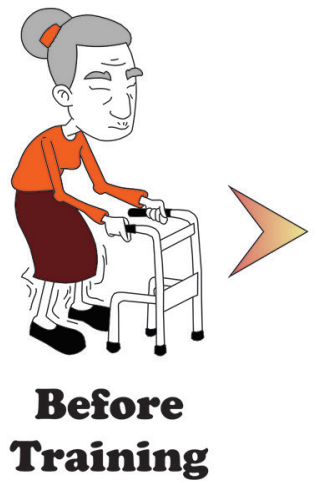

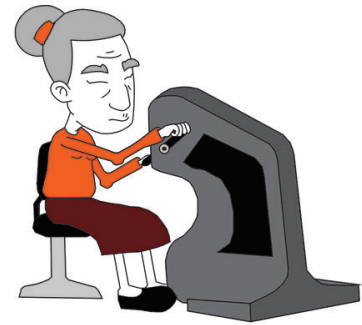

Arm Cycling Training
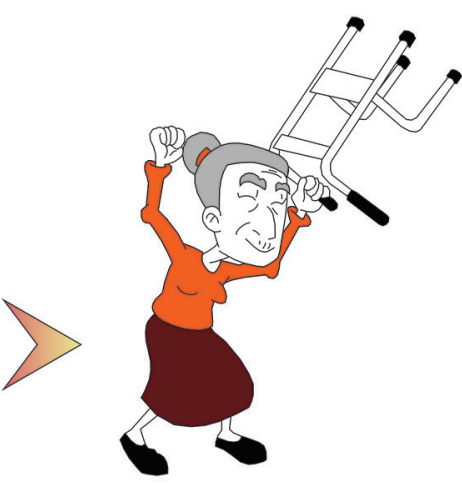

After Training 
Figure 3

On the left, this diagram shows the strong nerve connections from the brain to the upper (red) and lower (blue) limbs, as well as the connections in the spinal cord (green). In the middle, you can see that these connections are weakened after a stroke, resulting in a reduced ability to walk. The connections are grayed out, indicating that they are weaker. On the right, the person has trained and the connections have improved, causing the person to get better at walking.

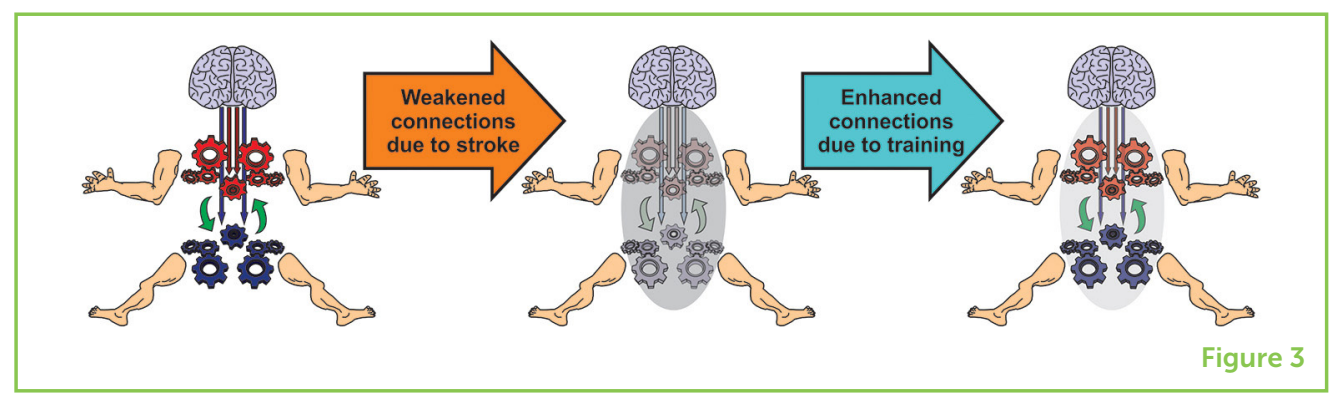

\section{WHY IS THIS IMPORTANT?}

Many of the tools used for rehabilitation after a stroke are very expensive to use and buy, and not all people who have had a stroke have lots of money. This means that a lot of people do not have access to the equipment that can help them get better at walking after a stroke. We want to help all people improve walking after a stroke by using simple equipment that can be found everywhere. Almost all community gyms have leg cycles and arm cycles. By using simple cycling exercises, even for training only their arms, people who have had a stroke may someday be able to use their legs and walk again.

\section{ORIGINAL SOURCE ARTICLE}

Kaupp, C., Pearcey, G. E. P., Klarner, T., Sun, Y., Cullen, H., Barss, T. S., et al. 2018. Rhythmic arm cycling training improves walking and neurophysiological integrity in chronic stroke: the arms can give the legs a helping hand in rehabilitation. J. Neurophysiol. 119:1095-112. doi: 10.1152/jn.00570.2017

\section{REFERENCES}

1. Zehr, E. P., Barss, T. S., Dragert, K., Frigon, A., Vasudevan, E. V., Haridas, C., et al. 2016. Neuromechanical interactions between the limbs during human locomotion-an evolutionary perspective and translation to rehabilitation. Exp. Brain Res. 234:3059-81. doi: 10.1007/s00221-016-4715-4

2. Zehr, E. P., Hundza, S. R., and Vasudevan, E. V. 2009. The quadrupedal nature of human bipedal locomotion. Exerc. Sport Sci. Rev. 37:102-8. doi: 10.1097/ JES.0b013e31819c2ed6

3. Barzi, Y., and Zehr, E. P. 2008. Rhythmic arm cycling suppresses hyperactive soleus H-reflex amplitude after stroke. Clin. Neurophysiol. 119:1443-52. doi: 10.1016/j.clinph.2008.02.016

4. Klarner, T., Barss, T. S., Sun, Y., Kaupp, C., Loadman, P. M., and Zehr, E. P. 2016. Exploiting interlimb arm and leg connections for walking rehabilitation: a training intervention in stroke. Neural Plast. 2016:1517968. doi: $10.1155 / 2016 / 1517968$ 
5. Klarner, T., Barss, T. S., Sun, Y., Kaupp, C., Loadman, P. M., and Zehr, E. P. 2016. Long-term plasticity in reflex excitability induced by five weeks of arm and leg cycling training after stroke. Brain Sci. 6:E54. doi: 10.3390/brainsci6040054

6. Kaupp, C., Pearcey, G. E. P., Klarner, T., Sun, Y., Cullen, H., Barss, T. S., et al. 2018. Rhythmic arm cycling training improves walking and neurophysiological integrity in chronic stroke: the arms can give the legs a helping hand in rehabilitation. J. Neurophysiol. 119:1095-112. doi: 10.1152/jn.00570.2017

SUBMITTED: 01 August 2018; ACCEPTED: 07 February 2019; PUBLISHED ONLINE: 28 February 2019.

EDITED BY: Daniel W. Wesson, University of Florida, United States

CITATION: Pearcey GEP and Zehr EP (2019) How the Arms Help the Legs Get Better at Walking After Stroke. Front. Young Minds 7:30. doi: 10.3389/frym.2019.00030

CONFLICT OF INTEREST STATEMENT: The authors declare that the research was conducted in the absence of any commercial or financial relationships that could be construed as a potential conflict of interest.

COPYRIGHT @ 2019 Pearcey and Zehr. This is an open-access article distributed under the terms of the Creative Commons Attribution License (CC BY). The use, distribution or reproduction in other forums is permitted, provided the original author(s) and the copyright owner(s) are credited and that the original publication in this journal is cited, in accordance with accepted academic practice. No use, distribution or reproduction is permitted which does not comply with these terms.

\section{YOUNG REVIEWERS}

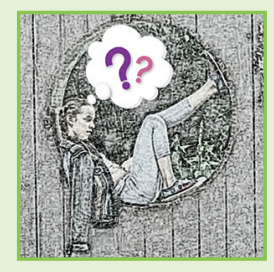

\section{ALYSSA, AGE: 12}

I love math and science especially when my parents like my grades. I enjoy horseback riding and gymnastics, when I do not fall. I adore dogs and puppies, because who does not? Sometimes I like to act and sew mostly when I am sick. But my favorite thing to do is to debate and travel with my family.

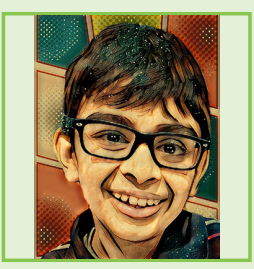

\section{ARITRO, AGE: 10}

I am 10 years old and I hope to become a Scientist someday. When I am not playing with my friends, my hobbies are reading, playing piano, as well as swimming and tennis. This may sound funny, but I like to sing in the bathroom. I also have an avid interest in trains, and am working with my father to build an $\mathrm{N}$-scale model railroad. I also really like learning about the environment and have been gardening with my mom since I was very little. I enjoy math, science, social studies, and art in school. 


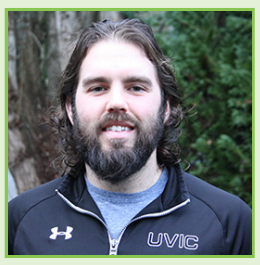

\section{AUTHORS}

\section{GREGORY E. P. PEARCEY}

I am a Ph.D. student studying Human Neuroscience at University of Victoria on Vancouver Island, on the western coast of Canada. I received an undergraduate degree in Kinesiology and a Master's of Science (Exercise Physiology) degree at Memorial University of Newfoundland, on the eastern coast of Canada. I have always been fascinated by the capability of humans to control their movements and adapt to training, which are the areas where my studies are focused. Outside of my studies, I enjoy playing with my dogs, lifting heavy weights, downhill skiing, and playing ice hockey. Follow along as I pursue my passion for everything exercise- and sport-related agregorypearcey on Twitter.

\section{E. PAUL ZEHR}

I have a Ph.D. (Neuroscience) and am a Science Communicator, Professor, Author, Martial Artist, and Principal Investigator of the Rehabilitation Neuroscience Laboratory at the University of Victoria. My research focuses on adaptations in the nervous system to strength training and walking after stroke and spinal cord injury. I enjoyed writing my science books "Becoming Batman," "Inventing Iron Man," "Project Superhero," and "Chasing Captain America: How Advances in Science, Engineering and Biotechnology Will Produce a Superhuman." These books use superheroes as metaphors to explore the science of human potential. I blog for Psychology Today and Scientific American magazines and you can find me at www.zehr.ca or @E_PaulZehr on twitter. *pzehr@uvic.ca 